\title{
I-gel for Positive Pressure Ventilation
}

\author{
Shyam Krishna Maharjan' \\ 'Department of Anesthesiology and Intensive care, Kathmandu medical college, Kathmandu, Nepal.
}

\section{ABSTRACT}

Introduction: I-gel is a relatively new supra-glotitc airway device which is claimed to be superior to laryngeal mask airway. It can be used ingeneral anesthesia with spontaneous ventilation as well as with positive pressure ventilation.This study was designed to assess whether I-gel creates adequate laryngeal seal during positive pressure ventilation in patients undergoing laparoscopic surgery.

Methods: A prospective randomized study was made among the 60 patients who underwent laparoscopic cholecystectomy under general anesthesia. Airway was managed with either I-gel insertion or endotracheal intubation and positive pressure ventilation in 30 patients each. Airway pressure, end-tidal $\mathrm{CO}_{2}$ and oxygen saturation were monitored and compared between two groups. Inhaled and exhaled tidal volume, minute volume were recorded and leak volume and leak fraction was calculated and compared between two groups.

Results: Oxygenation and ventilation (oxygen saturation and end-tidal carbon dioxide pressure) was within normal limit in both groups and comparable. Leak volume in tracheal tube group was $25.33 \pm 12.41 \mathrm{ml}$ and in l-gel group it was $26.43 \pm 13.19 \mathrm{ml}$. Leak fraction was $0.0487 \pm 0.023$ and $0.0417 \pm 0.022$ in tracheal group and I-gel group respectively. The airway pressure during $\mathrm{CO}_{2}$ pneumoperitoneumwas $20.55 \pm 3.25 \mathrm{~cm} \mathrm{H}_{2} \mathrm{O}$ in tracheal tube group and $20.21 \pm 3.97 \mathrm{~cm}$ $\mathrm{H}_{2} \mathrm{O}$ in I-gel group and there was no significant leak in either group. Statistically, there was no significant difference in leak volume, leak fraction and airway pressure between the two groups.

Conclusions: I- gel may be an alternate to tracheal tube during general anesthesia with positive pressure ventilation in patients with normal airway pressure with acceptable leak, adequate oxygenation and ventilation.

Keywords: I gel; Laparoscopic cholecystectomy; positive pressure ventilation; tracheal intubation.

\section{INTRODUCTION}

Different supraglottic devices are being used since last many years for maintaining airway and positive pressure ventilation during general anesthesia. Laryngeal mask airway and perilaryngeal airway (cobra tube) are among them and "I gel" is new addition to these devices. The l-gel is made of soft thermoplastic elastomer, gel like and transparent as well. It doesn't have an inflatable cuff but effectively covers the perilaryngeal area for ventilation. Different studies have shown that its insertion is easier and faster than conventional laryngeal mask airways. ${ }^{3,5}$

Classic laryngeal mask airway (LMA), another supraglottic airway device has inflatable cuff which creates some pressure in hypopharynx and has

Correspondence: Dr. Shyam Krishna Maharian, Department of Anesthesiology and Intensive care, Kathmandu medical college, Kathmandu, Nepal. Email: Shyammaharjan2@hotmail.com 
collapsible shaft making positioning unstable. I gel has no inflatable cuff with minimal pressure effect in hypopharynx. It has broad and stiff shaft which acts as buccal cavity stabilizer and bite block as well. The stiff shaft facilitates easy insertion and also prevents from dislodgement. It has separate gastric channel through which proper size suction tube can be passed for gastric decompression and aspiration of contents. There are reports of use of I gel during difficult intubation, ventilation and fiber optic intubation with the aid of the device..$^{8,17}$

There are many reports of I-gel use in spontaneously breathing patients during anesthesia but few reports of use in during positive pressure ventilation. As it creates effective seal around the laryngeal aperture, it can be used in patients with moderate airway pressure during mechanical ventilation. ${ }^{2}$ There are many reports of use of I gel in children for spontaneous as well as positive pressure ventilation. ${ }^{3}$

\section{METHODS}

After the approval from the institutional ethics committee, 60 patients of ASA I and II, scheduled for elective laparoscopic cholecystectomy were included in this study. The 30 patients were allocated in tracheal tube group and another 30 in I-gel group. Patients with acute or chronic lung disease, cases with chest deformities, difficult intubation cases, diabetic and patients with esophageal reflux disease and morbidly obese patients were excluded from the study.

We used Fabiusplus Drager anesthesia machine with built in computerized pressure gauze, spirometer and ventilator with volume control mode. Before induction of anesthesia, anesthesia workstation was checked as per manufacturer's guideline. Routine monitoring was used including electrocardiography, heart rate, pulse oximetry, noninvasive blood pressure and end-tidal $\mathrm{CO}_{2}$.

Anesthesia was induced with intravenous pethidine $1.0 \mathrm{mg} / \mathrm{kg}$, lignocaine $40 \mathrm{mg}$ and propofol $2.0 \mathrm{mg} /$ $\mathrm{kg}$. Vecuronium $0.1 \mathrm{mg} / \mathrm{kg}$ was given after confirming adequate hand ventilation. After two minutes of positive pressure ventilation, either tracheal tube or I-gel placement was done in randomized way by experienced Anesthesiologist. Tracheal tube size of 7.5 $\mathrm{mm}$ internal diameter in females and $8.0 \mathrm{~mm}$ size in males was used. l-gel selection was done according to manufacturer's manual relating to weight: size three was used for patients less than 50 kgand size four for patients weighing $50-90 \mathrm{~kg}$.

Adequate placement of device was confirmed by chest movement after gentle bag ventilation, chest auscultation and end tidal $\mathrm{CO}_{2}$ waveforms. Gentle manipulation, rotation was done if there was any leak from the I gel. Gastric insufflation was recorded by auscultation over the epigastrium after bag ventilation and instituting mechanical ventilation with set tidal volume. Failure of I-gel was recorded when there was audible leak, not improved with minor manipulations and tracheal intubation was done to continue the anesthesia.

Anesthesia was maintained with $1-2 \%$ isoflurane with $50 \%$ oxygen with air. The lungs were ventilated with $8-10 \mathrm{ml}$ per $\mathrm{kg}$ of tidal volume and respiratory rate of 12-14 per minutes to maintain $\mathrm{ETCO}_{2}$ of $30-40 \mathrm{mmHg}$. The inspiratory to expiratory ratio was set at 1:2. At the end of surgical procedure, anesthetic agents were discontinued; residual effect of vecuronium was reversed with $0.05 \mathrm{mg} / \mathrm{kg}$ of neostigmine and $0.01 \mathrm{mg} /$ $\mathrm{kg}$ of glycopyrrolate. The airway devices were removed when the respiratory efforts were adequate and stable.

Airway pressure, inhaled or set tidal volume, exhaled tidal volume, minute volume were recorded after placement of airway device, during pneumoperitoneum and after release of $\mathrm{CO}_{2}$ pneumoperitoneum. Intraperitoneal pressure during pneumoperitoneum was kept between 10-12 $\mathrm{mmHg}$.

The leak volume, the difference between inhaled(set) tidal volume and exhaled tidal volume and the leak fraction i.e. leak volume divided by inhaled tidal volume was calculated and compared between two groups. In order to calculate sample size, we considered the previous study where leak fraction of 0.2 was taken as significant and 0.15 as standard deviation, using two sample study design and use of t-test for comparison of group means. ${ }^{1}$ With significance level of $5 \%$ and $80 \%$ power, we need 15 patients in each group.

Statistical analysis was done using SPSS for windows 16 and data were reported mean plus/minus standard deviation. Intergroup comparison was made using independent samples t-test (Levene's test for equality of variances) and p-value less than 0.05 was taken as statistically significant between the groups.

\section{RESULTS}

The two groups were comparable in age, gender, height and weight.Body mass index was also comparable and no patients were morbidly obese. Male female ratio was 4:26 in tracheal tube group and 5:25 in I-gel group, ASA status I: II was 20:10and 22:8 in tracheal tube group and I-gel group respectively. Duration of anesthesia and surgery were also comparable (Table 1).

Airway pressure was $15.81 \pm 3.39 \mathrm{~cm} \mathrm{H}_{2} \mathrm{O}$ before pneumoperitoneum and $20.55 \pm 3.25 \mathrm{~cm} \mathrm{H}_{2} \mathrm{O}$ during 
$\mathrm{CO}_{2}$ pneumoperitoneum in tracheal tube group; $14.64 \pm$ $3.00 \mathrm{cmH}_{2} \mathrm{O}$ and $20.21 \pm 3.17 \mathrm{cmH}_{2} \mathrm{O}$ in l-gel group. The airway pressure steadily increased after gas insufflations in both group and there was no audible leak and no significant change in exhaled tidal volume in the groups. At the same time oxygen saturation was maintained between $99-100 \%$ and end tidal $\mathrm{CO}_{2}$ between $30-40 \mathrm{mmHg}$ in both tracheal tube and I-gel group (Table 2).

On analysis of the leak volume, i.e. the difference between inhaled tidal volume and exhaled tidal volume, there were no clinically and statistically significant differences between the two groups. Set tidal volume was $474.00 \pm 59.35 \mathrm{ml}$ and $482.20 \pm 81.71 \mathrm{ml}$ and exhaled tidal volume was $448.67 \pm 75.15 \mathrm{ml}$ and $455.77 \pm 81.40 \mathrm{ml}$ in tracheal tube group and I-gel group respectively. Mean Leak volume was $25.33 \pm$ $12.41 \mathrm{ml}$ in tracheal tube group and $26.43 \pm 13.19 \mathrm{ml}$ in I-gel group (P 0.846) (Table 2).

\begin{tabular}{|llll|}
\hline \multicolumn{4}{|c|}{ Table 1. Patient's demographic characters, ASA physical status and duration of anesthesia and } \\
surgery & (number \pm Standard Deviation). \\
\hline Parameters & \multicolumn{1}{c|}{ Tracheal tube group } & I gel group & P value \\
Age (years) & $42.61 \pm 14.89$ & $45.90 \pm 14.81$ & 0.896 \\
Gender, M:F & $4: 26$ & $5: 25$ & 0.247 \\
Weight (Kilogram) & $55.64 \pm 8.91$ & $57.34 \pm 11.11$ & 0.83 \\
Height (feet) & $4.97 \pm 0.45$ & $4.90 \pm 0.48$ & \\
Body mass index(BMI) $\mathrm{kg} / \mathrm{m}^{2}$ & $25.6-26.0$ & $25.9-26.4$ & 0.419 \\
ASA status, I:Il & $20: 10$ & $22: 8$ & 0.470 \\
Duration of Anesthesia(minute) & $49.55 \pm 14.69$ & $53.57 \pm 17.38$ & \\
Duration of surgery (minute) & $40.37 \pm 13.5$ & $44.37 \pm 15.2$ & \\
\hline
\end{tabular}

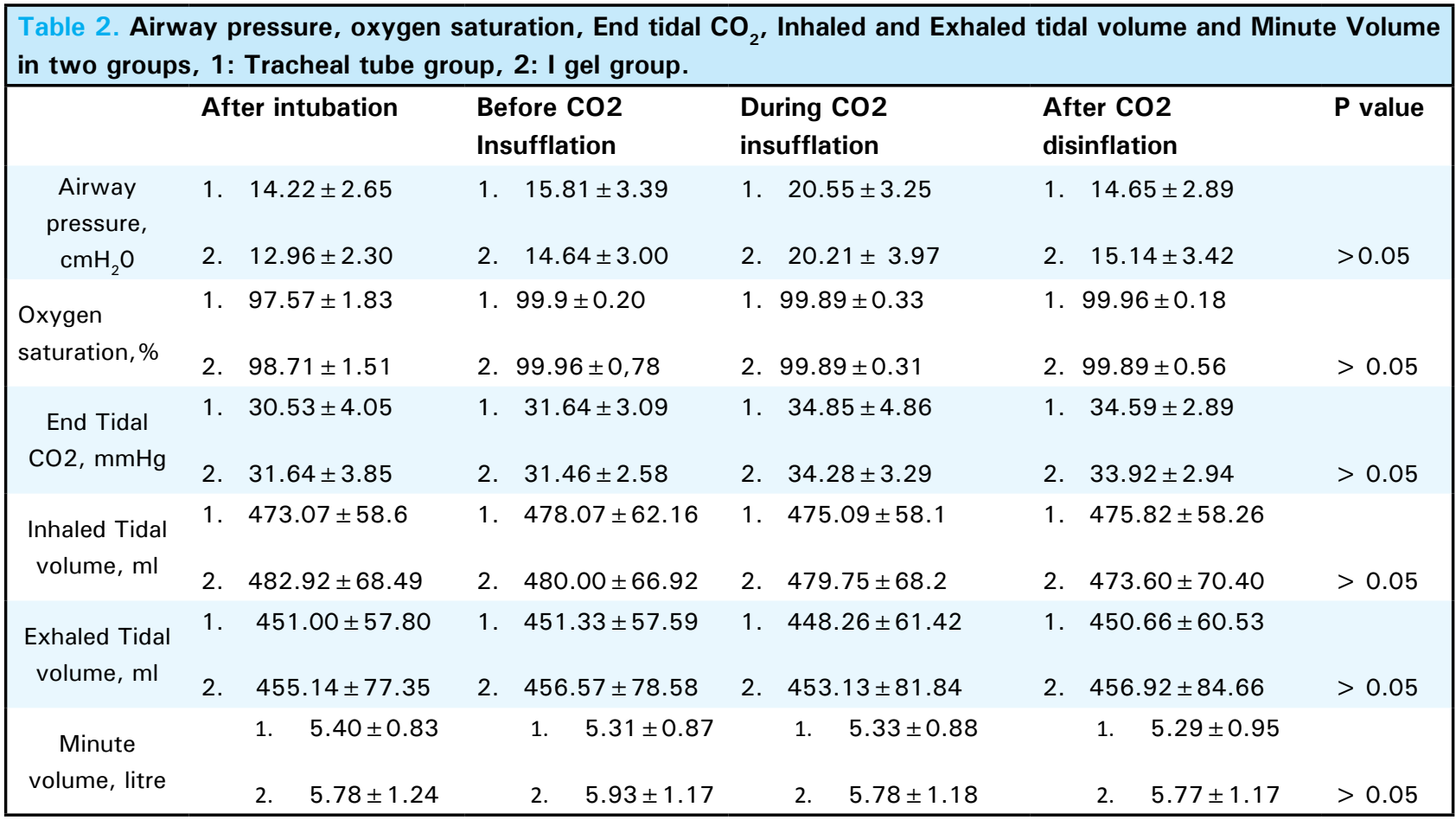


On analysis of leak volume before and during the $\mathrm{CO}_{2}$ pneumoperitoneum, when the airway pressure was 13-15 $\mathrm{cmH}_{2} \mathrm{O}$ before pneumoperitoneum to 25-28 $\mathrm{cmH}_{2} \mathrm{O}$ during pneumoperitoneum, it was $26.74 \mathrm{cmH}_{2} \mathrm{O}$ and $27.83 \mathrm{cmH}_{2} \mathrm{O}$ in tracheal tube group and 24.43 $\mathrm{cmH}_{2} \mathrm{O}$ and $26.62 \mathrm{cmH}_{2} \mathrm{O}$ in I-gel group, which were comparable. The leak fraction i.e. leak volume divided by inspired tidal volume was $0.0468 \pm 0.023$ in tracheal group and $0.0452 \pm 0.021$ in l-gel group which were also comparable (Table 3). Different studies have shown that leak fraction of $<0.20$ are clinically insignificant. ${ }^{1}$

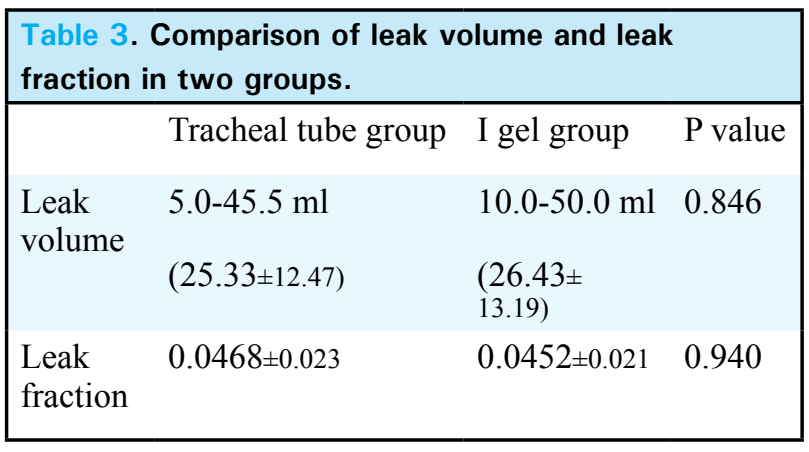

All the l-gel placement was in single (first) attempt, minor manipulations were needed in four cases and there was no total failure.There were no episodes of hypoxia, hypercarbia, laryngospasm, bronchospasm, during intraanesthetic period and clinically evident regurgitation and pulmonary aspiration till follow up to 24 hours after the procedure.

\section{DISCUSSION}

Tracheal tubes are being used for mechanical ventilation since last many years, as there is no definite alternate to these tubes. Laryngeal masks were used in some extent for same after 1990's but didn't get popular because of more failure rates and gas leak on moderate pressure. Other supraglottic devises also came into scene but didn't get popular because of the same problems. Recently I-gel is introduced and it can be used both for anesthesia with spontaneous ventilation and some studies showed that it can be used for mechanical ventilation as well. ${ }^{1,2}$

There are few reports of use of I-gel with mechanical ventilation with muscle relaxation. We also used I-gel for mechanical ventilation during general anesthesia for laparoscopic cholecystectomy with as good results as tracheal tubes. There are various reported advantages of supraglottic airway device compared to tracheal tubes during positive pressure ventilation i.e. lower incidence of sore throat, ${ }^{10}$ less hemodynamic stress response, ${ }^{7}$ better oxygenation duringemergence and fast case turnover. ${ }^{1}$ Therefore, nowadays, there is increasing trend of using supraglottic airway devices especially l-gel for positive pressure ventilation in patients with less risk of aspiration and moderate airway pressure..$^{1,2}$

We found that the I-gel placement was comparatively easy and can be used with patients with moderate airway pressure like during general anesthesia with positive pressure ventilation, even in laparoscopic surgery. There was clinically acceptable leak during peak airway pressure of $25-28 \mathrm{cmH}_{2} \mathrm{O}$ and similar trend was seen in patients with tracheal tube group. Uppal $\mathrm{V}$ et al compared l-gel and tracheal tube performances during pressure controlled ventilation, but they compared the devices in same patients. They reported that both devices have similar leaks at 15 and $25 \mathrm{cmH}_{2} \mathrm{O}$ airway pressure and I-gel is a reasonable alternate to tracheal tube during positive pressure ventilation with moderate airway pressure. ${ }^{1}$ Our study also showed acceptable leak volume and leak fraction up to the airway pressure of $28 \mathrm{cmH}_{2} \mathrm{O}$ in I-gel group and comparable to tracheal tube group. We used volume control mode of ventilation as there was no provision of pressure control mode in anesthesia machine.

Bimala Sharma et al compared Proseal LMA and I-gel during positive pressure ventilation in patients who underwent laparoscopic cholecystectomy. They compared respiratory mechanics, minute volume, peak airway pressure, end tidal $\mathrm{CO}_{2}$ and oxygen saturation. They concluded that both devices provided optimal ventilation and oxygenation and oropharyngeal seal pressure was $35.6 \mathrm{cmH}_{2} \mathrm{O}$ for I gel and $38.9 \mathrm{cmH}_{2} \mathrm{O}$ for PLMA. ${ }^{2,6}$ We didn't measure the leak pressure but there was no clinically significant leak up to $28 \mathrm{cmH}_{2} \mathrm{O}$ of peak airway pressure.

Beylack et al evaluated I gel in 50 children above 50 $\mathrm{kg}$ undergoingshort duration surgery. The first time success rate was $100 \%$, there was no laryngeal leakand mean seal pressure was $24.9 \mathrm{cmH}_{2} \mathrm{O} .{ }^{3}$ Gatward $\mathrm{JJ}$ et al evaluated size $4 \mathrm{l}$-gel in 100 nonparalyzed patients, $86 \%$ success in first attempt insertion, mean insertion time was 15 seconds, $7 \mathrm{ml} / \mathrm{kg}$ of expired tidal volume was achieved in $96 \%$ cases and median leak pressure was $24 \mathrm{cmH}_{2} \mathrm{O} .{ }^{4}$ We also observed faster insertion, verygood success rate and adequate minute volume to maintain ventilation and oxygenation.

Ayman SA El-Aziz compared pressure control mode and volume control mode of ventilation with the use of I-gel during elective laparoscopic surgery in fifty six patients. He reported that I-gel can be used safely without significant leak during laparoscopic cholecystectomy and there was no significant differences in hemodynamics, gas exchange and intraoperative blood gas parameters. ${ }^{16}$ 
Use of l-gel in difficult intubation cases, fiber optic intubation through the device and use even in resuscitation has been described. ${ }^{11-15}$ Though tracheal tube intubation is ideal for mechanical ventilation, in difficult intubation cases and in patients who warrant less hemodynamic response, I-gel can be used.

I-gel is not recommended for positive pressure ventilation in patients with low lung compliance such as in patients with chronic obstructive pulmonary disease, as there will be excess leak from the perilaryngeal area with inadequate oxygenation and ventilation and at the same time gastric distension leading to postoperative increment of nausea and vomiting.

Large scale study is needed to confirm and reconfirm these results of usefulness of I gel during positive pressure ventilation. We didn't study the leak pressure and other unwanted effects of I gel like sore throat and pharyngeal trauma which may be important if we use the device regularly.

\section{CONCLUSIONS}

I-gel may be the reasonable alternate to tracheal tube during general anesthesia with positive pressureventilation in patients with normal lung compliance. This study showed that ventilation and oxygenation was well maintained and leakvolume and airway pressure were similar in both I-gel group and tracheal tube group of patients during laparoscopic cholecystectomy.

\section{REFERENCES}

1. Uppal V, Fletcher G, Kinsella J. Comparison of the I gel with the cuffed tracheal tube during pressure controlled ventilation. BJA.2009;102:264-8.

2. Sharma B, Sehgal R, Sahai C, Sood J. PLMA vs. I gel: A comparative evaluation of respiratory mechanics in laparoscopic cholecystectomy. Journal of Anesthesiology. 2010; 26(4):451-7.

3. Beylack L,Bordes M, Senjen F. The I gel, a single usesupraglottic airway device with a noninflattable cuff and an esophageal vent, an observational study in children. ActaAnesthesiologica Scandinavia. 2009 March;53(3):376-9.

4. Gatward JJ, Cook TM, Seller C. Evaluation of the size 4 I gel airway in one hundred non paralyzed patients. Anesthesia. 2008 Oct;63(10):1124-30.

5. Richez, Saltel L,Torrielli R,Cros AM. A new single use supraglottic airway device with a non inflatable cuff and an esophageal vent: an observational study of I gel.Anesth Analog. 2008 Apr;106(4):1137-9.

6. Singh T, Gupta M, Tandan M. Comparison of clinical performance of I gel with LMA-proseal in elective surgeries. Indian Journal of Anesthesia. 2009;53(3):302-5.

7. Jindal P, Rizvi A, Sharma JP. Is I gel a new revolution among supraglottic airway devices? A comparative evaluation. Middle East J Anesthesiol. 2009 Feb;20(1):53-8.

8. Theiler LG, Kleine BM, Kaiser D. Crossover comparison of the laryngeal mask Supreme and the I gel in simulated difficult airway scenario in anesthetized patients. Anesthesiology. 2009;111:55-62.
9. Weber U, Oguz R, Potura LA. Comparison of the I gel and the LMA-Unique laryngeal mask airway in patients with mild to moderate obesity during elective short term surgery. Anesthesia. 2011 Jun;66(6):481-7.

10. Keijzer C, Buitelaar DR, Efthymiou KM. A comparison of post operative sore throat and neck complains after the use of I gel and la premiere LMA: a double blinded randomized controlled trial. AnesthAnalog. 2009;109:1092-4.

11. Sharma S, Rogers R, Popat M. The I gel airway for ventilation and rescue ventilation. Anesthesia. 2007;62:412-23.

12. Michalek P, Hodkinson P, Donaldson W. Fiberoptic intubation through an I gel supraglottic airway in two patients with predicted difficult airway and intellectual disability. Anesth analog. 2008 May;106(5):1501-4.

13. Soar J. The I gel supraglottic airway and resuscitation-some initial thoughts. Resuscitation. 2007 Jul;74(1):197.

14. Joshi NA, Baird M, Cook TM. Use of an I gel for airway rescue. Anesthesia. 2008;63:1010-26

15. Campbell J, Michalek P, Deighan M. I gel supraglottic airway for rescue airway management and as a conduit for intubation in a patient with acute respiratory failure. Resuscitation. 2009 Aug;80(8):963.

16. Ayman SA El-Aziz. New supraglottic airway device; I gel in elective laparoscopic cholecystectomy using volume controlled ventilation versus pressure controlled ventilation. Journal of American science. 2011;7(11):447-53. 